\title{
A PROPER GENERALIZATION OF BANACH PRINCIPLE FOR NADLER TYPE MAPPINGS IN CONE b-METRIC SPACES OVER BANACH ALGEBRAS
}

\author{
Faruk Develi $^{\text {a* }}$ (D), Muttalip Ozavsara ${ }^{\text {a }}$ Stojan Radenovic ${ }^{\text {(iD }}$ \\ ${ }^{a}$ Department of Mathematics, Yildiz Technical University, Istanbul, Turkey \\ fdeveli@yildiz.edu.tr (*corresponding author),mozavsar@yildiz.edu.tr \\ ${ }^{b}$ Faculty of Mechanical Engineering University of Belgrade, Serbia \\ radens@beotel.rs
}

\begin{abstract}
In this paper, we first consider Nadler type contractions with the generalized Lipschitz constant $k$ holding $r(k)<1$ instead of $r(s k)<1$ where $r(k)$ is the spectral radius of $k$ and $s \geq 1$ is the coefficient of the underlying cone $b$-metric spaces over Banach algebras. Then, we prove the corresponding fixed point theorem for such mappings. Finally, we compare our result with one obtained by the case $r(s k)<1$ by introducing some proper examples.
\end{abstract}

Keywords: Nadler mappings, Banach algebra, Cone b-metric

\section{Introduction}

In 1922, Banach introduced the fixed point theorem for contraction mappings in metric spaces. Afterwards, many researchers studied its applications and generalizations. For example, in 1967, Nadler [1] extended Banach's contraction principle to set-valued contraction mappings. Also, in 1998, Czerwik [2] introduced the notion of b-metric space as a generalization of the usual metric space and proved Banach's contraction principle in such space. Then, by following the results obtained in [1] and [2], Suzuki [8] proved a theorem, which is a generalization of Nadler's fixed point theorem, in b-metric space.

On the other hand, the notion of Banach space-valued metric established by Huang and Zhang [3] had attracted attention of many authors from 2007 to 2010. However, in 2010, Du [4] showed that some fixed point theorems in this setting are equivalent to their counterparts in 
the usual metric space. After that, in 2013, Liu and Xu [5] constructed the cone metric space over Banach algebra and gave some fixed point theorems by means of spectral radius and normal solid cones. Also they introduced an example to show that Banach's contraction principle in cone metric spaces over Banach algebras is not equivalent to the usual one. In 2014, Xu and Radenovic [12] obtained the results of [5] by removing the condition of normality for solid cone. In 2015, on Banach algebras, cone b-metric spaces were introduced by Huang and Radenovic [9]. Then, Wardowski [6] defined H-cone metric structure by combining Nadler type contraction with cone metric space on Banach space. Later, inspired by Wardowski and taking into account the results of [4], Ozavsar [7] established H-cone bmetric space over Banach algebra.

In this paper, following results of Suzuki [8] and Ozavsar [7], we generalize the main result of [7] by extending $r(s k) \in(0,1)$ to $r(k) \in(0,1)$ in $\mathrm{H}$-cone b-metric with respect to a cone bmetric space over Banach algebras.

\section{Preliminary}

A real Banach algebra $A$ is a real Banach space together with an operation of multiplication satisfied the following properties (for all $\mathrm{x}, \mathrm{y}, \mathrm{z} \in \mathrm{A}, \alpha \in \mathbb{R}$ )

1. $(x y) z=x(y z)$,

2. $x(y+z)=x y+x z$ and $(x+y) z=x z+y z$,

3. $\alpha(x y)=(\alpha x) y=x(\alpha y)$,

4. $\|x y\| \leq\|x\|\|y\|$.

Let $\mathrm{A}$ has a unit (i.e. multiplicative identity) e such that $\mathrm{ex}=\mathrm{xe}=\mathrm{x}$ for all $\mathrm{x} \in \mathrm{A}$. An element $\mathrm{x} \in \mathrm{A}$ is said to be invertible if there is an inverse element $\mathrm{y} \in \mathrm{A}$ such that $\mathrm{xy}=\mathrm{yx}=\mathrm{e}$. The inverse of $x$ is denoted by $x^{-1}$. For more details, we refer the reader to Rudin [13]. Now let us recall the concepts of cone to obtain a partial ordered relation on $\mathrm{A}$. A subset $\mathrm{P}$ of $\mathrm{A}$ is called a cone of $\mathrm{A}$ if

1. $\mathrm{P}$ is non-empty closed and $\{\theta, \mathrm{e}\} \subset \mathrm{P}$;

2. $\alpha \mathrm{P}+\beta \mathrm{P} \subset \mathrm{P}$ for all non-negative real numbers $\alpha, \beta$;

3. $\mathrm{P}^{2}=\mathrm{PP} \subset \mathrm{P}$;

4. $P \cap(-P)=\{\theta\}$,

where $\theta$ denotes the null of the Banach algebra $\mathrm{A}$. For a given cone $\mathrm{P} \subset \mathrm{A}$, we can define a partial ordering $\preccurlyeq$ with respect to $\mathrm{P}$ by $\mathrm{x} \preccurlyeq \mathrm{y}$ if and only if $\mathrm{y}-\mathrm{x} \in \mathrm{P}$. The notation $\mathrm{x} \prec \mathrm{y}$ will stand for $\mathrm{x} \leqslant \mathrm{y}$ and $\mathrm{x} \neq \mathrm{y}$, while $\mathrm{x} \ll \mathrm{y}$ for stand for $\mathrm{y}-\mathrm{x} \in$ intP, where intP denotes the interior of $\mathrm{P}$. If intP $\neq \varnothing$ then $\mathrm{P}$ is called a solid cone. If there exists a positive real number $\mathrm{K}$ such that for all $\mathrm{x}, \mathrm{y} \in \mathrm{A}$

$$
\theta \preccurlyeq \mathrm{x} \preccurlyeq \mathrm{y} \text { implies }\|\mathrm{x}\| \leq \mathrm{K}\|\mathrm{y}\| \text {, }
$$

then a cone $\mathrm{P}$ is called normal [3]. Now we shortly recall the spectral radius which is neccessary for the main result. Let $A$ be a Banach algebra with a unit e. The spectral radius of $\mathrm{x} \in \mathrm{A}$ as follows; 


$$
r(x)=\lim _{n \rightarrow \infty}\left\|x^{n}\right\|^{\frac{1}{n}}
$$

If $r(x)<1$, then $e-x$ is invertible (see [13]) and the inverse of $e-x$ is given by

$$
(e-x)^{-1}=\sum_{i=0}^{\infty} x^{i}
$$

From now on, we always suppose that $A$ is a real Banach algebra with unit e, $\mathrm{P}$ is a solid cone in $\mathrm{A}$, and $\preccurlyeq$ is a partial ordering with respect to $\mathrm{P}$.

Lemma 2.1 [12] Let $\mathrm{x}, \mathrm{y}$ be vectors in A. If $\mathrm{x}$ commutes with $\mathrm{y}$, then the followings hold:

1. $r(x y) \leq r(x) r(y)$

2. $r(x+y) \leq r(x)+r(y)$.

Definition 2.2 [9] Let $X$ be a nonempty set and $1 \leq \mathrm{s}$ be a constant. Let $\mathrm{d}$ be a mapping from $\mathrm{X} \times \mathrm{X}$ into $\mathrm{A}$. Then $(\mathrm{X}, \mathrm{d})$ is said to be a cone $\mathrm{b}$-metric space over $\mathrm{A}$ if the followings hold:

1. $\theta \leqslant d(x, y)$ and $d(x, y)=\theta$ if and only if $x=y$

2. $d(x, y)=d(y, x)$

3. $d(x, y) \leqslant s(d(x, z)+d(z, x))$

for all $x, y, z \in X$.

Definition 2.3 [9] Let $(X, d)$ be a cone b-metric space over Banach algebra $A, x \in X$ and $\left\{x_{n}\right\}$ be a sequence in $\mathrm{X}$. Then:

1. $\left\{x_{n}\right\}$ converges to $x$ whenever for each $c \in A$ with $\theta \ll c$ there is a naturel number $N$ such that $d\left(x_{n}, x\right) \ll c$ for all $n \geq N$. This is denoted by $\lim _{n \rightarrow \infty} x_{n}=x$ or $x_{n} \rightarrow x, n \rightarrow$ $\infty$.

2. $\left\{\mathrm{x}_{\mathrm{n}}\right\}$ is a Cauchy sequence whenever for each $\mathrm{c} \in \mathrm{A}$ with $\theta \ll \mathrm{c}$ there is a naturel number $\mathrm{N}$ such that $\mathrm{d}\left(\mathrm{x}_{\mathrm{n}}, \mathrm{x}_{\mathrm{m}}\right) \ll \mathrm{c}$ for all $\mathrm{n}, \mathrm{m} \geq \mathrm{N}$.

3. (X, d) said to be complete if every Cauchy sequence $\left\{X_{n}\right\}$ in $X$ is convergent.

Definition 2.4 [12] A sequence $\left\{u_{n}\right\} \subset P$ is a c-sequence if for each $\theta \ll c$ there exists $n_{0} \in \mathbb{N}$ such that $\mathrm{u}_{\mathrm{n}} \ll \mathrm{c}$ for $\mathrm{n}>\mathrm{n}_{0}$.

Lemma 2.5 [9] If $r(k)<1$, then $\left\{\mathrm{k}^{\mathrm{n}}\right\}$ is a c-sequence.

Lemma 2.6 [12] Let $\left\{u_{n}\right\}$ be a sequence in $P$. Suppose that $k \in P$ is an arbitrarily given vector and $\left\{u_{n}\right\}$ is a c-sequence in $P$. Then $\left\{\mathrm{ku}_{\mathrm{n}}\right\}$ is a c-sequence.

Lemma 2.7 [14] Let $\left\{\mathrm{x}_{\mathrm{n}}\right\}$ and $\left\{\mathrm{y}_{\mathrm{n}}\right\}$ be sequences in P. If $\left\{\mathrm{x}_{\mathrm{n}}\right\}$ and $\left\{\mathrm{y}_{\mathrm{n}}\right\}$ are c-sequences and $\alpha, \beta>0$, then $\left\{\alpha x_{n}+\beta y_{n}\right\}$ is a c-sequence.

Lemma 2.8 [11] If $u \preccurlyeq v$ and $v \ll w$, then $u \ll w$. 
Lemma 2.9 [12] Let $(X, d)$ be a complete cone b-metric space over $A$ and $\left\{x_{n}\right\} \subset X$ is a sequence that converges to $\mathrm{x} \in \mathrm{X}$, then we have

1. $\left\{d\left(x_{n}, x\right)\right\}$ is a c-sequence.

2. $\left\{d\left(x_{n}, x_{n+p}\right)\right\}$ is a c-sequence for any $p \in \mathbb{N}$.

Lemma 2.10 [7] Let $\mathrm{k} \in \mathrm{P}$ such that $\mathrm{r}(\mathrm{k})<1$. Then

$$
\sum_{\mathrm{i}=\mathrm{p}}^{\mathrm{n}} \mathrm{k}^{\mathrm{i}} \preccurlyeq \mathrm{k}^{\mathrm{p}}(\mathrm{e}-\mathrm{k})^{-1}
$$

for all $\mathrm{p} \in \mathbb{N}$.

Definition 2.11 (see [6], [7]) Let (X, d) be a cone b-metric space over a Banach space E with solid cone $P$ and let $N(X)$ be a collection of nonempty subsets of $X$. A mapping $H$ : $N(X) X$ $\mathrm{N}(\mathrm{X}) \rightarrow \mathrm{E}$ is called an $\mathrm{H}$-cone metric over a Banach space $\mathrm{E}$ with respect to $\mathrm{d}$ if for any $A_{1}, A_{2} \in N(X)$ the following conditons hold:

H1 $H\left(A_{1}, A_{2}\right)=\theta \Rightarrow A_{1}=A_{2}$,

H2 $\mathrm{H}\left(\mathrm{A}_{1}, \mathrm{~A}_{2}\right)=\mathrm{H}\left(\mathrm{A}_{2}, \mathrm{~A}_{1}\right)$,

H3 for all $\varepsilon \in \mathrm{E}$ with $\theta \ll \varepsilon$ and for all $\mathrm{x} \in \mathrm{A}_{1}$, there exists at least one $\mathrm{y} \in \mathrm{A}_{2}$ such that $\mathrm{d}(\mathrm{x}, \mathrm{y}) \preccurlyeq \mathrm{H}\left(\mathrm{A}_{1}, \mathrm{~A}_{2}\right)+\varepsilon$,

$\mathbf{H} 4$ one of the following holds:

i : for all $\varepsilon \in E$ with $\theta \ll \varepsilon$ there is at least one $x \in A_{1}$ such that $H\left(A_{1}, A_{2}\right) \preccurlyeq$ $\mathrm{d}(\mathrm{x}, \mathrm{y})+\varepsilon$ for all $\mathrm{y} \in \mathrm{A}_{2}$,

ii : for all $\varepsilon \in E$ with $\theta \ll \varepsilon$ there is at least one $x \in A_{2}$ such that $H\left(A_{1}, A_{2}\right) \preccurlyeq$ $d(x, y)+\varepsilon$ for all $y \in A_{1}$.

Definition 2.12 [7] Let (X,d) be a cone b-metric space over Banach algebra A. A mapping $\mathrm{H}: \mathrm{N}(\mathrm{X}) \times \mathrm{N}(\mathrm{X}) \rightarrow \mathrm{A}$ is called an $\mathrm{H}$-cone b-metric over $\mathrm{A}$ with respect to the cone b-metric space $\mathrm{d}$ if it holds the conditions (H1-H4) given above.

Lemma 2.13 [7] If a mapping $\mathrm{H}: \mathrm{N}(\mathrm{X}) \times \mathrm{N}(\mathrm{X}) \rightarrow \mathrm{A}$ is an H-cone b-metric over A with respect to the cone b-metric space $(X, d)$ over $A$, then $(N(X), H)$ is a cone b-metric space over $A$.

\section{Main results}

Lemma 3.1 (see [8]) Let $(X, d)$ be a cone $b$-metric space and $f(n)=-\left[-\log _{2} n\right]$ which is a function from $\mathbb{N}$ to $\mathbb{N} \cup\{0\}$. Then, the following condition holds

$$
d\left(x_{0}, x_{n}\right) \preccurlyeq s^{f(n)} \sum_{i=0}^{n-1} d\left(x_{i}, x_{i+1}\right)
$$

for all $\left(\mathrm{x}_{0}, \ldots, \mathrm{x}_{\mathrm{n}}\right) \in \mathrm{X}^{\mathrm{n}+1}$.

Proof. Since the proof is very similar to one of Lemma 5 given in [8], we omit it. 
Theorem 3.2 Let $(\mathrm{X}, \mathrm{d})$ be a complete cone $\mathrm{b}$-metric space over Banach algebra $\mathrm{A}$ and $\mathrm{P}$ be solid cone in $A$. Let $k \in$ intP with $r(k)<1$. Suppose that the mapping $T: X \rightarrow N(X)$ satisfies the following condition:

$$
\mathrm{H}(\mathrm{Tx}, \mathrm{Ty}) \preccurlyeq \mathrm{kd}(\mathrm{x}, \mathrm{y})
$$

for all $\mathrm{x}, \mathrm{y} \in \mathrm{X}$. Then, $\mathrm{T}$ has at least one fixed point in $\mathrm{X}$.

Proof. Let $\left\{\varepsilon_{n}\right\}$ be sequence in A such that for all $n \in \mathbb{N}$

$$
\theta \ll \varepsilon_{\mathrm{n}} \text { and } \varepsilon_{\mathrm{n}} \preccurlyeq \mathrm{k}^{2 \mathrm{n}}
$$

Let $\mathrm{x}_{0} \in \mathrm{X}$ and $\mathrm{x}_{1} \in \mathrm{Tx}_{0}$. If $\mathrm{H}\left(\mathrm{Tx}_{1}, \mathrm{Tx}_{0}\right)=\theta$ then $\mathrm{Tx}_{1}=\mathrm{Tx}_{0}$ and $\mathrm{x}_{1} \in \mathrm{Tx}_{1}$ which means that $\mathrm{T}$ has a fixed point. Let $\mathrm{H}\left(\mathrm{Tx}_{1}, \mathrm{Tx}_{0}\right) \neq \theta$. By (H3), there is a $\mathrm{x}_{2} \in \mathrm{Tx}_{1}$ such that

$$
\mathrm{d}\left(\mathrm{x}_{2}, \mathrm{x}_{1}\right) \preccurlyeq \mathrm{H}\left(\mathrm{Tx}_{1}, \mathrm{Tx}_{0}\right)+\varepsilon_{1} .
$$

So, by the induction, we get a sequence $\left\{\mathrm{x}_{\mathrm{n}}\right\}$ with $\mathrm{x}_{\mathrm{n}+1} \in \mathrm{Tx}_{\mathrm{n}}$ satisfying

$$
d\left(x_{n+1}, x_{n}\right) \preccurlyeq H\left(T x_{n}, T x_{n-1}\right)+\varepsilon_{n}, n=1,2, \ldots
$$

From (2), (3) and (4), we obtain the following inequalities:

$$
\begin{aligned}
& \mathrm{d}\left(\mathrm{x}_{\mathrm{n}+1}, \mathrm{x}_{\mathrm{n}}\right) \preccurlyeq H\left(\mathrm{Tx}_{\mathrm{n}}, \mathrm{Tx}_{\mathrm{n}-1}\right)+\varepsilon_{\mathrm{n}} \preccurlyeq \mathrm{kd}\left(\mathrm{x}_{\mathrm{n}}, \mathrm{x}_{\mathrm{n}-1}\right)+\varepsilon_{\mathrm{n}} \\
& \preccurlyeq \mathrm{k}\left(\mathrm{H}\left(\mathrm{Tx}_{\mathrm{n}-1}, \mathrm{Tx_{n } - 2}\right)+\varepsilon_{\mathrm{n}-1}\right)+\varepsilon_{\mathrm{n}} \\
& \preccurlyeq \mathrm{k}^{2} \mathrm{~d}\left(\mathrm{x}_{\mathrm{n}-1}, \mathrm{x}_{\mathrm{n}-2}\right)+\mathrm{k} \varepsilon_{\mathrm{n}-1}+\varepsilon_{\mathrm{n}} \\
& \cdots \\
& \preccurlyeq \mathrm{k}^{\mathrm{n}} \mathrm{d}\left(\mathrm{x}_{1}, \mathrm{x}_{0}\right)+\sum_{\mathrm{i}=1}^{\mathrm{n}} \mathrm{k}^{\mathrm{n}-\mathrm{i}} \varepsilon_{\mathrm{i}} \\
& \preccurlyeq \mathrm{k}^{\mathrm{n}} \mathrm{d}\left(\mathrm{x}_{1}, \mathrm{x}_{0}\right)+\sum_{\mathrm{i}=1}^{\mathrm{n}} \mathrm{k}^{\mathrm{n}-\mathrm{i}} \mathrm{k}^{2 \mathrm{i}} \\
& \preccurlyeq \mathrm{k}^{\mathrm{n}} \mathrm{d}\left(\mathrm{x}_{1}, \mathrm{x}_{0}\right)+\mathrm{k}^{\mathrm{n}}\left(\sum_{\mathrm{i}=1}^{\mathrm{n}} \mathrm{k}^{\mathrm{i}}\right) .
\end{aligned}
$$

Hence, by using Lemma 2.10, we get

$$
\mathrm{d}\left(\mathrm{x}_{\mathrm{n}+1}, \mathrm{x}_{\mathrm{n}}\right) \preccurlyeq \mathrm{k}^{\mathrm{n}} \mathrm{d}\left(\mathrm{x}_{1}, \mathrm{x}_{0}\right)+\mathrm{k}^{\mathrm{n}} \mathrm{k}(\mathrm{e}-\mathrm{k})^{-1}=\mathrm{k}^{\mathrm{n}} \lambda
$$

where $\lambda=d\left(x_{1}, x_{0}\right)+k(e-k)^{-1}$. Now, we will show that $\left\{x_{n}\right\}$ is a Cauchy sequence by using the function $\mathrm{f}$ defined in Lemma 3.1. Considering the item (1) in Lemma 2.1, we can choose $\ell \in \mathbb{N}$ such that $r\left(\mathrm{sk}^{2^{\ell}}\right)<1$. For $\mathrm{n}, \mathrm{m} \in \mathbb{N}$ with $\mathrm{n}<\mathrm{m} \leq \mathrm{n}+2^{\ell}$, by Lemma 3.1 and (5), we get

$$
d\left(x_{n}, x_{m}\right) \preccurlyeq s^{f(m-n)} \sum_{i=n}^{m-1} d\left(x_{i}, x_{i+1}\right)
$$




$$
\begin{aligned}
& \preccurlyeq s^{\ell} \sum_{i=n}^{m-1} k^{i} \lambda \preccurlyeq s^{\ell}\left(\sum_{i=n}^{\infty} k^{i}\right) \lambda \\
& =s^{\ell} k^{n} C
\end{aligned}
$$

where $\mathrm{C}=(\mathrm{e}-\mathrm{k})^{-1} \lambda$. Let $\mathrm{h}_{\mathrm{n}}=\mathrm{s}^{\ell} \mathrm{k}^{\mathrm{n}} \mathrm{C}$. By Lemmas 2.5, 2.6 and 2.7, it is obvious that the sequence $\left\{h_{n}\right\}$ is a c-sequence. So, for each $\theta \ll c$, there exists $N_{0} \in \mathbb{N}$ such that $d\left(x_{n}, x_{m}\right) \preccurlyeq$ $h_{n} \ll c$ for $n>N_{0}$. On the other hand, for $n, m \in \mathbb{N}$ with $n+2^{\ell}<m$, considering $\gamma=[(m-$ $\left.\mathrm{n}) / 2^{\ell}\right]$ together with (cbm3), we have

$$
d\left(x_{n}, x_{m}\right) \preccurlyeq \sum_{i=0}^{\gamma-1} s^{i+1} d\left(x_{n+i 2^{\ell}}, x_{n+(i+1) 2^{\ell}}\right)+s^{\gamma} d\left(x_{n+\gamma 2^{\ell}}, x_{m}\right) .
$$

Since $n+(i+1) 2^{\ell}-\left(n+i 2^{\ell}\right)=2^{\ell}$ and $m-\left(n+\gamma 2^{\ell}\right)<2^{\ell}$, by using (6), the following inequalities satisfy;

$$
\begin{gathered}
\mathrm{d}\left(\mathrm{x}_{\mathrm{n}+\mathrm{i} 2^{\ell}}, \mathrm{x}_{\mathrm{n}+(\mathrm{i}+1) 2^{\ell}}\right) \preccurlyeq \mathrm{s}^{\ell} \mathrm{k}^{\mathrm{n}+\mathrm{i} 2^{\ell}} \mathrm{C} \\
\mathrm{d}\left(\mathrm{x}_{\mathrm{n}+\gamma 2^{\ell}}, \mathrm{x}_{\mathrm{m}}\right) \preccurlyeq \mathrm{s}^{\ell} \mathrm{k}^{\mathrm{n}+\gamma 2^{\ell}} \mathrm{C} .
\end{gathered}
$$

Thus, by inserting (8) to (7), we obtain

$$
\begin{aligned}
& \mathrm{d}\left(\mathrm{x}_{\mathrm{n}}, \mathrm{x}_{\mathrm{m}}\right) \preccurlyeq \sum_{\mathrm{i}=0}^{\gamma-1} \mathrm{~s}^{\mathrm{i}+1+\ell} \mathrm{k}^{\mathrm{n}+\mathrm{i} 2^{\ell}} \mathrm{C}+\mathrm{s}^{\gamma+\ell} \mathrm{k}^{\mathrm{n}+\gamma 2^{\ell}} \mathrm{C} \\
& \preccurlyeq \mathrm{s}^{\ell+1}\left(\sum_{\mathrm{i}=0}^{\gamma} \mathrm{s}^{\mathrm{i}} \mathrm{k}^{\mathrm{n}+\mathrm{i} 2^{\ell}}\right) \mathrm{C}=\mathrm{s}^{\ell+1}\left(\sum_{\mathrm{i}=0}^{\gamma}\left(\mathrm{sk}^{2^{\ell}}\right)^{\mathrm{i}}\right) \mathrm{k}^{\mathrm{n}} \mathrm{C} \\
& \preccurlyeq \mathrm{s}^{\ell+1}\left(\mathrm{e}-\mathrm{sk}^{2^{\ell}}\right)^{-1} \mathrm{k}^{\mathrm{n}} \mathrm{C} .
\end{aligned}
$$

Let $g_{n}=s^{\ell+1}\left(e-s^{2^{\ell}}\right)^{-1} k^{n} C$. By Lemmas 2.5, 2.6 and 2.7, it is clear that the sequence $\left\{g_{n}\right\}$ is a c-sequence. So, for each $\theta \ll c$, there exists $N_{1} \in \mathbb{N}$ such that $d\left(x_{n}, x_{m}\right) \preccurlyeq g_{n} \ll c$ for $n>$ $\mathrm{N}_{1}$. Thus, for $\mathrm{N}=\max \left\{\mathrm{N}_{0}, \mathrm{~N}_{1}\right\}, d\left(\mathrm{x}_{\mathrm{n}}, \mathrm{x}_{\mathrm{m}}\right) \ll \mathrm{c}$ whenever $\mathrm{m}>\mathrm{n}>\mathrm{N}$. So, $\left\{\mathrm{x}_{\mathrm{n}}\right\}$ is a Cauchy sequence. The completeness of $X$ implies that there is a $x \in X$ such that $\left\{x_{n}\right\}$ converges to $x$. Therefore, since $\left\{d\left(x_{n}, x\right)\right\}$ is a c-sequence according to Lemma 2.9, for each $c \in$ intP, there exists $n_{0} \in \mathbb{N}$ such that $d\left(x_{n}, x\right) \ll \frac{c}{3 s}$ for $n \geq n_{0}$. Also, since $x_{n} \in T_{n-1}$ for $n \geq 1$, we obtain from (H3) that for all $n \in \mathbb{N}$ there is $y_{n} \in$ Tx such that

$$
\mathrm{d}\left(\mathrm{x}_{\mathrm{n}}, \mathrm{y}_{\mathrm{n}}\right) \preccurlyeq \mathrm{H}\left(\mathrm{Tx}_{\mathrm{n}-1}, \mathrm{Tx}\right)+\varepsilon_{\mathrm{n}} \preccurlyeq \mathrm{kd}\left(\mathrm{x}_{\mathrm{n}-1}, \mathrm{x}\right)+\mathrm{k}^{2 \mathrm{n}}
$$

By Lemmas 2.5, 2.6, 2.7 and 2.9, $\left\{k d\left(x_{n-1}, x\right)+k^{2 n}\right\}$ is a c-sequence. Hence, for $c \in \operatorname{intP}$, there is $\mathrm{n}_{1} \in \mathbb{N}$ such that

$$
d\left(x_{n}, y_{n}\right) \preccurlyeq k d\left(x_{n-1}, x\right)+k^{2 n} \ll \frac{2 c}{3 s}
$$

for $\mathrm{n} \geq \mathrm{n}_{1}$. Consequently, for $\mathrm{n} \geq \max \left\{\mathrm{n}_{0}, \mathrm{n}_{1}\right\}$, we have 


$$
d\left(y_{n}, x\right) \preccurlyeq s\left(d\left(y_{n}, x_{n}\right)+d\left(x_{n}, x\right)\right) \ll \frac{c}{3}+\frac{2 c}{3}=c
$$

which implies by Lemma 2.8 that

$$
d\left(y_{n}, x\right) \ll c
$$

Finally, we see that $\mathrm{y}_{\mathrm{n}} \rightarrow \mathrm{x}, \mathrm{n} \rightarrow \infty$, meaning that since Tx is closed, we have $\mathrm{x} \in \mathrm{T} \mathrm{x}$.

Example 3.3 Let $X=[0,1], A=C_{\mathbb{R}}^{1}[X]$ and define a norm on $A$ by $\|\mathrm{f}\|=\|\mathrm{f}\|_{\infty}+\left\|\mathrm{f}^{\prime}\right\|_{\infty}$. Define multiplication in $\mathrm{A}$ as the usual pointwise multiplication. Then $\mathrm{A}$ becomes a real Banach algebra with the multiplicative unit $e=1$. The set $P=\{f \in A \mid f(t) \geq 0$ for all $t \in X\}$ is a non-normal cone (see [10]). Consider a mapping $d: X \times X \rightarrow A$ defined by $d(x, y)(t)=$ $|x-y|^{2} e^{t}$. We can easily show that $(X, d)$ is a cone $b$-metric space with $s=2$ on the Banach algebra $A$. Let $N(X)=\{[0, x] \mid x \in X\}$. Define a mapping $H([0, x],[0, y])(t)=|x-y|^{2} e^{t}$. It is easily seen that $(N(X), H)$ is an $H$-cone b-metric space over $A$. Now let us define $T: X \rightarrow N(X)$ by $\mathrm{Tx}=\left[0, \sqrt{3} \sin \frac{\mathrm{x}}{2}\right]$. T holds the contraction condition (2) with $\mathrm{k} \in$ intP defined by $\mathrm{k}(\mathrm{t})=\frac{3}{4}$ as follows;

$$
H(T x, T y)(t)=\left|\sqrt{3} \sin \frac{x}{2}-\sqrt{3} \sin \frac{y}{2}\right|^{2} e^{t} \leq \frac{3}{4}|x-y|^{2} e^{t}=k(t) d(x, y)(t) .
$$

Clearly, $r(s k) \notin(0,1)$, but $r(k) \in(0,1)$. As seen, Theorem 3.2 of [7] can not be applied to this mapping, while $T$ has a fixed point with respect to Theorem 3.2.

Example 3.4 See that $A=\mathbb{R}^{2}$ equipped with the pointwise multiplication and the usual norm is a Banach algebra. Let $P=\left\{(x, y) \in \mathbb{R}^{2} \mid 0 \leq x, y\right\}, X=\mathbb{R}^{2}$ and $p \in \mathbb{R}$ with $1<p$. We define a mapping $\mathrm{d}: \mathrm{X} \times \mathrm{X} \rightarrow \mathrm{A}$ as $\mathrm{d}\left(\left(\mathrm{x}_{1}, \mathrm{y}_{1}\right),\left(\mathrm{x}_{2}, \mathrm{y}_{2}\right)\right)=\left(\left|\mathrm{x}_{1}-\mathrm{x}_{2}\right|^{\mathrm{p}},\left|\mathrm{y}_{1}-\mathrm{y}_{2}\right|^{\mathrm{p}}\right)$. Then, by using the inequality $(a+b)^{p} \leq 2^{p}\left(a^{p}+b^{p}\right)$ for all $a, b \geq 0$ and the properties of the cone $P$, we can show that $(\mathrm{X}, \mathrm{d})$ is a cone b-metric with coefficient $\mathrm{s}=2^{\mathrm{p}}$ over $\mathrm{A}$. Consider a closed subset $\mathrm{a} \otimes \mathrm{b}$ of $\mathrm{X}$ defined by $\mathrm{a} \otimes \mathrm{b}=\{(\mathrm{x}, \mathrm{y}) \in \mathrm{X} \mid 0 \leq \mathrm{x} \leq \mathrm{a}, 0 \leq \mathrm{y} \leq \mathrm{b}\}$ for $0 \leq \mathrm{a}, \mathrm{b}$ and $\mathrm{N}(\mathrm{X})=\{\mathrm{a} \otimes \mathrm{b} \mid 0 \leq \mathrm{a}, \mathrm{b}\}$. Then it is clear that a mapping $\mathrm{H}: \mathrm{N}(\mathrm{X}) \times \mathrm{N}(\mathrm{X}) \rightarrow \mathrm{A}$ given by $\mathrm{H}\left(\mathrm{a}_{1} \otimes \mathrm{b}_{1}, \mathrm{a}_{2} \otimes \mathrm{b}_{2}\right)=\left(\left|\mathrm{a}_{1}-\mathrm{a}_{2}\right|^{\mathrm{p}},\left|\mathrm{b}_{1}-\mathrm{b}_{2}\right|^{\mathrm{p}}\right)$ is H-cone b-metric space over A. Now let us define $\mathrm{T}: \mathrm{X} \rightarrow \mathrm{N}(\mathrm{X})$ as $\mathrm{T}(\mathrm{X}, \mathrm{y})=\left|\frac{\cos \mathrm{x}}{2}\right| \otimes\left|\frac{\operatorname{cosy}}{2}\right|$. Then, one can easily show that

$$
\mathrm{H}\left(\mathrm{T}\left(\mathrm{x}_{1}, \mathrm{y}_{1}\right), \mathrm{T}\left(\mathrm{x}_{2}, \mathrm{y}_{2}\right)\right) \preccurlyeq \mathrm{kd}\left(\left(\mathrm{x}_{1}, \mathrm{y}_{1}\right),\left(\mathrm{x}_{2}, \mathrm{y}_{2}\right)\right)
$$

where $\mathrm{k}=\left(\frac{1}{\mathrm{~s}}, \frac{1}{\mathrm{~s}}\right) \in \mathrm{intP}$. Thus $\mathrm{T}$ satisfies the condition of Theorem 3.2, it has a fixed point.

Note that the main theorem of [7] is not applicable to the example given above because of $\mathrm{r}(\mathrm{sk})=1$.

\section{Acknowledgments}

The authors are thankful to the editor and the referees for their valuable comments and suggestions which have been useful for the improvement of this paper. 


\section{References}

[1] Nadler, S.B., “Multi-valued contraction mappings”, Pac. J. Math. 30(2) (1969) : 475488.

[2] Czerwik, S., "Contraction mappings in b-metric spaces", Acta Math Inf Univ Ostraviensis 1(1) (1993) : 5-11.

[3] Huang, L.G., Zhang, X., "Cone metric spaces and fixed point theorems of contractive mappings”, J. Math. Anal. Appl. 332(2) (2007) : 1468-1476.

[4] Du, W.-S., "A note on cone metric fixed point theory and its equivalence”, Nonlinear Anal. 72(5) (2010) : 2259-2261.

[5] Liu, H., Xu, S., "Cone metric spaces with Banach algebras and fixed point theorems of generalized Lipschitz mappings”, Fixed Point Theory Appl. 2013(1) (2013) : 320.

[6] Wardowski, D., “On set-valued contractions of Nadler type in cone metric spaces”, Appl. Math. Lett. 24(3) (2011) : 275-278.

[7] Ozavsar, M., "Nadler mappings in cone b-metric spaces over Banach algebras", Rendiconti del Seminario Matematico (2018).

[8] Suzuki, T., "Basic inequality on a b-metric space and its applications", Journal of inequalities and applications 2017(1) 2017 : 256.

[9] Huang, H., Radenovic, S., "Common fixed point theorems of generalized Lipschitz mappings in cone b-metric spaces over Banach algebras and applications”, J. Non. Sci. Appl. 8(5) (2015) : 787-799.

[10] Rezapour, S., Hamlbarani, R., "Some notes on the paper "Cone metric spaces and fixed point theorems of contractive mappings””, J. Math. Anal. Appl. 345(2) (2008) : 719724.

[11] Radenovic, S., Rhoades, B.E., "Fixed point theorem for two non-self mappings in cone metric spaces”, Comput. Math. Appl. 57(10) (2009) : 1701-1707.

[12] Xu, S., Radenovic, S., "Fixed point theorems of generalized Lipschitz mappings on cone metric spaces over Banach algebras without assumption of normality”, Fixed Point Theory Appl. 2014(1) (2014) : 102.

[13] Rudin, W., Functional Analysis, 2nd edn. McGraw-Hill, New York (1991).

[14] Kadelburg, Z., Radenovic, S., "A note on various types of cones and fixed point results in cone metric spaces”, Asian J. Math. Appl. (2013). 